\title{
Evaluación microbiológica de quesos frescos artesanales comercializados en la ciudad de Chachapoyas-Amazonas, 2016
}

\section{Microbiological evaluation of fresh handmade cheeses marketed in the city of Chachapoyas-Amazonas, 2016}

\author{
*Ernestina R. Vásquez-Castro ${ }^{1}$, Zoila R. Guevara-Muñoz ${ }^{2}$
}

\section{RESUMEN}

El presente trabajo evaluó la calidad microbiológica del queso fresco artesanal comercializado en la ciudad de Chachapoyas durante el año 2016. Se analizó 40 muestras de quesos comercializados en mercados y panaderías de la ciudad de Chachapoyas, evaluando la presencia de coliformes totales, coliformes fecales y estafilococos coagulasa positiva. El 100\% de las muestras de quesos frescos artesanales analizados mostraron recuentos de coliformes totales, coliformes fecales y estafilococos coagulasa positiva superiores a los límites establecidos en la NTP 202.195, 2004, verificándose que la totalidad de quesos analizados no estaban aptos para el consumo humano.

Palabras claves: Coliformes totales, Coliformes fecales, Estafilococos coagulasa positiva, queso fresco artesanal.

\begin{abstract}
The present work characterized the microbiological quality of fresh artisanal cheese commercialized in the city of Chachapoyas, Amazonas, in 2016. Forty samples of cheese from markets and bakeries were analyzed, markets and bakeries of the city of Chachapoyas, evaluating the presence of total coliforms, fecal coliforms and staphylococci Coagulase positive. All of those samples, showed total coliform counts, faecal coliforms and coagulase positive staphylococci, concentration higher than the limits established in NTP 202.195, 2004. The study determined that the artisanal cheese of Chachapoyas is not advisable for human consumption.
\end{abstract}

Keywords: Total coliforms, fecal coliforms, coagulase positive staphylococci, artisanal fresh cheese.

\footnotetext{
${ }^{1}$ *Microbióloga. Universidad Nacional Toribio Rodríguez de Mendoza de Amazonas. Correo electrónico: ernestina.vasquez@untrm.edu.pe

${ }^{2}$ Bióloga. Universidad Nacional Toribio Rodríguez de Mendoza de Amazonas. Correo electrónico: zoila.guevara@untrm.edu.pe
} 


\section{INTRODUCCIÓN}

La principal actividad económica en la Provincia de Chachapoyas es la agricultura y la ganadería, que concentra el 42,22\% de la PEA provincial; siendo la actividad pecuaria una de las más desarrolladas. Aquí se encuentra dos de las cuatro principales cuencas lecheras de la región Amazonas, Leymebamba y Molinopampa (Municipalidad provincial de Chachapoyas, 2010). Entre los productos derivados de la leche y de mayor consumo en Chachapoyas, están los quesos frescos artesanales, exhibiendo características típicas propias de gran preferencia por los pobladores locales; son producidos y comercializados durante todo el año en los mercados y panaderías, en tanto, las malas prácticas de control de calidad de la leche empleada en su elaboración, las formas inadecuadas de transporte y comercialización propician la contaminación con microorganismos, los cuales pueden ser patogénicos y de importancia en salud pública.

El peligro de contaminación microbiana del queso fresco, tiene su origen en la contaminación inicial de la materia prima (Lanchípa y Sosa, 2003), en el proceso de elaboración y en la etapa de comercialización (Cristóbal y Maurtua, 2003).

Lanchípa y Sosa (2003) determinaron que la mitad de los quesos comercializados en la ciudad de Tacna, sobrepasaron los estándares microbiológicos de la NTP 202.087, presentando elevada carga de Staphylococcus aureus y Escehrichia coli. De manera similar, Luján et al. (2006) al evaluar quesos frescos artesanales en tres distritos de Lima, encontró que el $80 \%$ de las muestras analizadas presentaron cargas de $S$. aureus por encima de $10^{2} \mathrm{UFC} / \mathrm{g}$, LMP establecido por la NTP202.087.

Los quesos artesanales, son en general productos muy manipulados, desde su producción, transporte y comercialización, por lo que son muy propensos de contaminación, principalmente de origen microbiológica; los cuales pueden ocasionar brucelosis hasta intoxicaciones alimentarias. Entretanto, es importante realizar evaluaciones continuas de la calidad microbiológica de los quesos para determinar su calidad sanitaria, recomendar buenas prácticas en el control de calidad de la leche a emplear, y salvaguardar las adecuadas condiciones de higiene en su comercialización.

La presente investigación tuvo como objetivo evaluar la calidad microbiológica del queso fresco artesanal comercializado en la ciudad de Chachapoyas en el año 2016.

\section{MATERIAL Y MÉTODOS}

La recolección y análisis de las muestras de queso fresco se realizó entre los meses de julio a noviembre de 2016, analizándose un total de 40 muestras, en una frecuencia de 8 muestras por mes. Los quesos de aproximadamente $170 \mathrm{~g}$ fueron adquiridas directamente del vendedor en dos mercados y dos panaderías de la ciudad de Chachapoyas, codificadas individualmente y transportadas en bolsas plásticas de polietileno y colocados en caja de poliestireno expandido con gel refrigerante a $4^{\circ} \mathrm{C}$, el procesamiento fue inmediato en el Laboratorio de Biología de la Universidad Nacional Toribio Rodríguez de Mendoza de Amazonas.

Antes del procesamiento de las muestras para el análisis microbiológico, se determinó el pH utilizando un potenciómetro Hanna Instruments modelo HI 8424 y la prueba de lugol.

\section{Análisis microbiológico}

Se empleó la metodología propuesta por la Comisión Intenacional para las Especificaciones Microbiológicas de los Alimentos (ICMSF), descrita por Thatcher y Clark (1973), que a continuación se describe:

Según el Método 2 de preparación y dilución de los homogenizados de los alimentos, especificados por la ICMSF, se homogenizó $10 \mathrm{~g}$ de muestra de queso fresco en $90 \mathrm{~mL}$ de diluyente, agua peptonada $0,1 \%$ durante un tiempo no mayor a 2,5 min y se dejó en reposo para la reactivación de los microorganismos, lo que constituyó la dilución $10^{-1}$. A partir de esta dilución patrón, se realizaron diluciones decimales consecutivas hasta obtener una concentración de $10^{-4}$ en agua peptonada.

Para la prueba de coliformes totales se inocularon cada una de las diluciones preparadas en tubos de caldo Lauril Sulfato Triptosa, (CLST) con campana de Durham invertida, utilizando tres tubos por cada dilución. Se incubó a $37^{\circ} \mathrm{C}$ durante 24 y 48 horas, se anotaron los tubos que mostraron producción de gas. Se verificó que los tubos de caldo lauril sulfato triptosa seleccionados sean positivos de organismos coliformes transfiriendo una asada de cada tubo a otro tubo de caldo lactosa bilis verde brillante, con campana de Durham invertida, y se incubaron durante 24 y $48 \mathrm{~h} \mathrm{a} 37^{\circ} \mathrm{C}$ y se observó la producción de gas. Se anotó el número de tubos confirmados como positivos de coliformes en cada dilución. Se compararon los resultados anotados de tubos gas positivos con la tabla del Número más probable (NMP) y se anotó el que corresponde al número de tubos positivos de cada dilución.

Para la determinación de coliformes de origen fecal, 
se seleccionaron los tubos gas positivo de coliformes totales y se inoculó un asa de caldo de cada tubo elegido en un tubo de caldo lactosa bilis verde brillante y en otro de caldo peptonado. Se incubaron los tubos inoculados a $44,5^{\circ} \mathrm{C}$ en baño maría, durante 24 y 48 horas. Transcurrido el tiempo de incubación se tomó una alícuota de $3 \mathrm{~mL}$ de cada uno de los tubos de caldo peptonado en un tubo de ensayo estéril y se añadió $0,3 \mathrm{~mL}$ del reactivo de Kovacs para observar la producción de indol. Los cultivos gas positivo en caldo lactosa bilis verde brillante e indol positivo se consideraron como positivo para coliformes fecales.

En las pruebas de confirmación de E. coli, se sembró por estría un asa de cada tubo de caldo gas positivo de coliformes fecales en una placa de agar ENDO y se incubó a $37^{\circ} \mathrm{C}$ por 24 horas. Se tomó una colonia representativa (nucleada con o sin brillo metálico) y se sembró en estría en una placa de agar nutritivo. Se incubó a $37^{\circ} \mathrm{C}$ por 24 horas. Transcurrida la incubación, se realizó una tinción Gram para confirmar la presencia de bacilos gram negativos no esporulados. Se eligió una colonia de la placa y se inoculó en tubo con agar nutritivo en plano inclinado. Tras su incubación a $37^{\circ} \mathrm{C}$ por 24 horas se inoculó una asa en medios diferenciales para realizar las pruebas bioquímicas: Indol, lisina hierro, rojo de metilo, Voges-Proskauer Citrato, además de la prueba de fermentación en agar hierro triple azúcar y la tinción de Gram.

Para el recuento de $S$. aureus se realizaron siembras a partir de las diluciones preparadas en placas de agar Baird-Parker, por duplicado, se incubó a $37^{\circ} \mathrm{C}$ por 30 a $48 \mathrm{~h}$. Transcurrido el período de incubación se realizó el recuento de colonias características y se eligieron cinco colonias por placa y se inocularon cada una en tubos conteniendo caldo infusión cerebro corazón (BHI) y se incubó a $37^{\circ} \mathrm{C}$ por $24 \mathrm{~h}$, transcurrido el tiempo se realizó la confirmación de $S$. aureus mediante las pruebas de coagulasa, catalasa, y DNAsa, así como la tinción de Gram.

Para el análisis de datos, el número de microrganismos de los análisis microbiológicos respectivos fueron tabulados las medias y comparados con los límites permisibles según la NTP 202.195, 2004.

\section{RESULTADOS}

Los quesos frescos artesanales en la ciudad de Chachapoyas-Amazonas, son comercializados sin refrigeración y envueltos en plástico (Figura 1). Las muestras colectadas durante el periodo de estudio registraron valores de $\mathrm{pH}$ próximo a 6 , y todas las muestras fueron negativas a la prueba de lugol.
En la Tabla 1, se presentan los datos del análisis microbiológico de las muestras colectadas de queso fresco artesanal. Los coliformes totales registraron valores $>1100 \mathrm{NMP} / \mathrm{g}$ en todas las muestras de quesos frescos colectadas, superiores a lo establecido en la NTP 2002.195 (2004). Los coliformes fecales registraron recuentos mayores al nivel crítico establecido en la NTP 202.195 (2004), un 55\% de las muestras analizadas mostraron valores de recuentos microbianos superiores a la norma antes indicada. Los recuentos de estafilococos coagulasa positiva mostraron valores superiores al establecido en la NTP 202.195, 2004 (Instituto Nacional de Defensa de la Competencia y de la Protección de la Propiedad Intelectual-Indecopi, 2004).

En la Figura 2 se muestran los datos del análisis microbiológico de coliformes fecales en las muestras de quesos frescos artesanales comercializados en los mercados y panaderías de la ciudad de Chachapoyas, donde se aprecia que el total de establecimiento muestreados registra valores por encima de los límites establecidos en la NTP 202.195, 2004. Asimismo, el recuento de estafilococos coagulasa positiva de los quesos frescos artesanales también registra valores por encima de los límites establecidos en la NTP 202.195, 2004 (Figura 3).

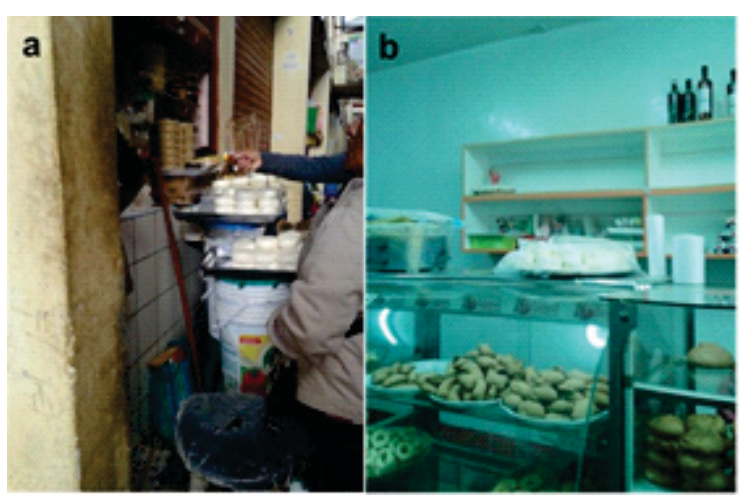

Figura 1. Comercialización de quesos frescos artesanales en la ciudad de ChachapoyasAmazonas, 2016. a) Mercado, b) Panadería. 
Tabla 1. Análisis microbiológico de las muestras de quesos frescos artesanales comercializados en la ciudad de Chachapoyas-Amazonas, 2016

\begin{tabular}{|c|c|c|c|c|}
\hline Microorganismos & $\begin{array}{l}\text { NMP/g } \\
\text { UFC/g }\end{array}$ & $\begin{array}{l}\text { Número de } \\
\text { muestras } \\
\text { analizadas }\end{array}$ & $\begin{array}{c}\text { Porcentaje de } \\
\text { muestras analizadas } \\
\text { en relación al total } \\
\text { de muestras }\end{array}$ & $\begin{array}{c}\text { Límite } \\
\text { aceptable } \\
\text { NTP 202.195. } \\
2004\end{array}$ \\
\hline Coliformes totales & $>1100$ & 40 & 100 & $10^{2}-10^{3}$ \\
\hline \multirow{6}{*}{ Coliformes fecales } & $<9$ & 0 & 0 & \multirow{6}{*}{$10-10^{2}$} \\
\hline & $10-74$ & 9 & 45 & \\
\hline & $75-139$ & 5 & 25 & \\
\hline & $140-204$ & 2 & 10 & \\
\hline & $205-269$ & 0 & 0 & \\
\hline & $>270$ & 4 & 20 & \\
\hline \multirow{6}{*}{$\begin{array}{l}\text { Estafilococos } \\
\text { coagulasa positiva }\end{array}$} & $<9,3 \times 10^{3}$ & 0 & 0 & \multirow{6}{*}{$10-10^{2}$} \\
\hline & $9,4 \times 10^{3}-1,4 \times 10^{5}$ & 8 & 40 & \\
\hline & $1,5 \times 10^{5}-2,8 \times 10^{5}$ & 2 & 10 & \\
\hline & $2,9 \times 10^{5}-4,2 \times 10^{5}$ & 6 & 30 & \\
\hline & $4,3 \times 10^{5}-5,6 \times 10^{5}$ & 2 & 10 & \\
\hline & $>5,7 \times 10^{5}$ & 2 & 10 & \\
\hline
\end{tabular}
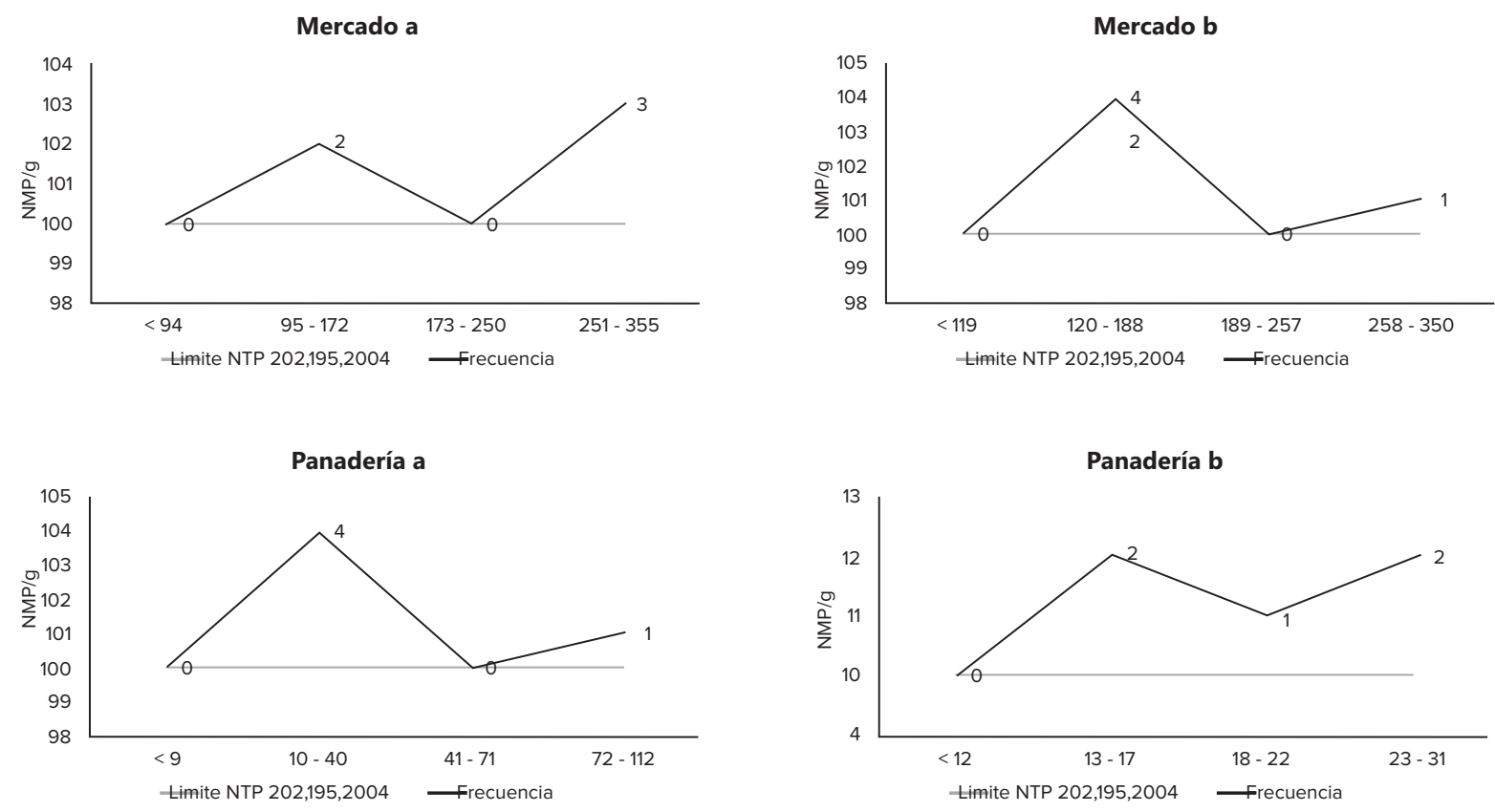

Figura 2. Análisis microbiológico de coliformes fecales en las muestras de quesos frescos artesanales comercializados en mercados y panaderías de la ciudad de Chachapoyas-Amazonas, 2016 

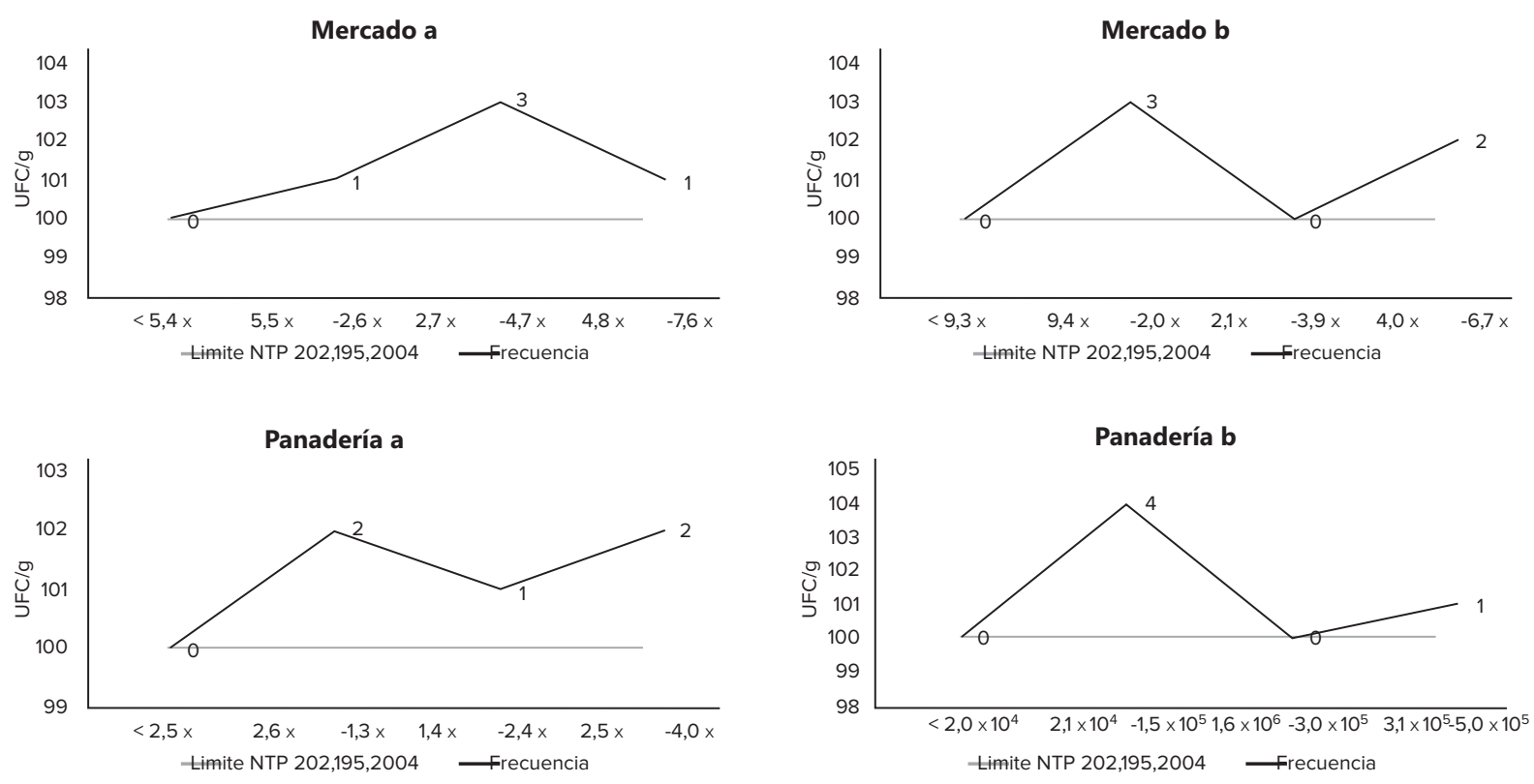

Figura 3. Análisis microbiológico de estafilococos coagulasa positiva en las muestras de quesos frescos artesanales comercializados en mercados y panaderías de la ciudad de Chachapoyas-Amazonas, 2016

\section{DISCUSIÓN}

El 100\% de los quesos frescos artesanales analizados de dos mercados y dos panaderías en la ciudad de Chachapoyas entre los meses de julio a noviembre de 2016 registraron valores de coliformes totales $>1100$ $\mathrm{NMP} / \mathrm{g}$, superiores a los límites establecidos en la NTP 202.195 (2004); resultados similares fueron reportados por Cristobal y Maurtua (2003).

La determinación de coliformes totales es importante porque según Apolinario et al. (2014), elevados valores de recuento de microorganismos, son indicadores de posible presencia de patógenos como E. coli. Lo valores encontrados indican una posible deficiencia en la calidad higiénica y sanitaria del producto (Brant et al., 2007), puesto que son microorganismos ambientales.

Pinto et al. (2011), mencionan que la presencia de coliformes fecales es un indicativo de manipulación incorrecta y falta de aplicación de buenas prácticas de manufactura, pudiendo ser un indicativo de contaminación de origen fecal, evidenciando que los quesos comercializados en la ciudad de Chachapoyas representan un alto riesgo para la salud de los consumidores., concordando con lo encontrado por Cristobal y Maurtua (2003) cuando evaluaron quesos frescos artesanales de la ciudad de Lima.

La presencia de S. aureus y los valores elevados de $\mathrm{UFC}^{-1}$, podría indicar una contaminación a partir de la piel, la boca o las fosas nasales de portadores de la infección que manipularon el queso, siendo también otras fuentes de contaminación el material, el equipo de trabajo y las materias de origen animal (Cristobal y Maurtua, 2003). También, puede deberse a problemas de procesamiento como: inadecuada pasteurización, higiene inadecuada de equipamientos y manipuladores, temperaturas inadecuadas de almacenamiento (Apolinário et al., 2014). Valores de recuentos similares fueron reportados por Cristobal y Maurtua (2003), y Luján et al. (2006) en quesos frescos artesanales comercializados Lima.

\section{CONCLUSIONES}

Los quesos frescos artesanales comercializados en Chachapoyas, registraron valores microbiológicos superiores a los límites establecidos en la NTP 202.195 (2004), no presentando calidad microbiológica adecuada para su comercialización.

Es necesario la implementación de mejoras en las buenas prácticas de manufactura en la producción de quesos frescos artesanales, fiscalización por los organismos competentes con la finalidad que los consumidores de quesos frescos artesanales no tengan riesgos que afecte su salud. 


\section{REFERENCIAS BIBLIOGRÁFICAS}

Apolinário, T. C., dos Santos, G. S., y Lavorato, J. A. (2014). Avaliação da qualidade microbiológica do queijo minas frescal produzido por laticínios do estado de Minas Gerais. Revista do Instituto de Laticínios Cândido Tostes, 69(6), 433442.

Brant, L. D., Fonseca, L. M., y Silva, M. C. (2007). Avaliação da qualidade microbiológica do queijo-de-minas artesanal do Serro-MG Microbiological quality of artisanal minas cheese, manufactured in the region of Serro-MG. Arquivo Brasileiro de Medicina Veterinária e Zootecnia, 59(6), 1570-1574.

Cristóbal, R. L., y Maurtua, D. J. (2003). Evaluación bacteriológica de quesos frescos artesanales comercializados en Lima, Perú, y la supuesta acción bactericida de Lactobacillus spp. Rev. Panam. Sal. Publ, 24,157-163.

Instituto Nacional de Defensa de la Competencia y de la Protección de la Propiedad Intelectual (Indecopi). (2004). Norma Técnica Peruana 202.195. Lima: Indecopi.

Lanchipa, L., y Sosa, Y. (2003). Evaluación de la carga microbiana patógena en la elaboración del queso fresco en el distrito de Tacna. Universidad Nacional Jorge Basadre Grohmann. Tacna-Perú. D i s p o n i b 1 e e $\mathrm{n}$ http://www.unjbg.edu.pe/coin2/pdf/0104 0700503.pdf

Luján, D., Valentín, M., y Molina, M. (2017). Evaluación de la presencia de Staphylococcus aureus en quesos frescos artesanales en tres distritos de Lima-Perú. RESPYN Revista de Salud Pública y Nutrición, 7(2). Disponible en $<$ http://respyn.uanl.mx/index.php/respyn/ article/view/166>

Pinto, F. G. S., Souza, M., Saling, S., y Moura, A. C. (2011). Qualidade microbiológica de queijo minas frescal comercializado no município de Santa Helena, PR, Brasil. Arquivos do Instituto Biológico, 78(2), 191-198.

Municipalidad Provincial de Chachapoyas. (2010). Plan de desarrollo provincial concertado
-Chachapoyas 2011-2021. Municipalidad Provincial de Chachapoyas.

Thatcher, F. S., Clark, D. S., y García, B. M. (1973). Análisis microbiológico de los alimentos (No. QR 115. M5218). Zaragoza: Acribia. 